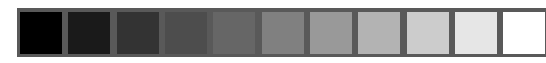

\title{
O que há de perspicácia e o que há de ingenuidade nos moti- vos apresentados pelos indígenas sobre a escola?
}

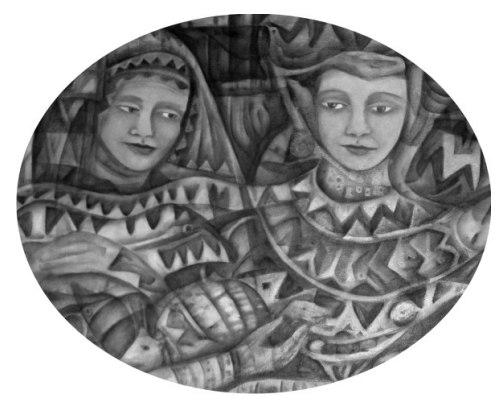

Márcio Roberto Vieira Cavalcante ${ }^{* *}$

\section{Resumo}

O presente texto enfoca a questão da educação escolar em comunidades indígenas no Estado do Acre. A proposta é fazer um balanço de como vem sendo produzida a educação indígena no Estado e analisa as implicações de tal processo. Por fim, propõe um contexto onde a construção da educação escolar indígena possa ocorrer a partir do enfoque do perspectivismo ameríndio.

Palavras-chave: Escola indígena. Cultura. Perspectivismo.

\begin{abstract}
What is shrewd and what is naïve in the reasons put forward by Indians on the school? The present text focuses on the issue of school education in indigenous communities in the State of the Acre. The proposal is to take stock of how the indigenous education is being produced in the State and to analyze the implications of such a process. Finally, a context where the construction of the indigenous schooling can occur from the approach of the Amerindian perspectivism is proposed.
\end{abstract}

Keywords: Indigenous school. Culture. Perspectivism.

\footnotetext{
"Artigo produzido como resultado do curso de formação de Técnicos em Educação Escolar Indígena, promovido pela Secretária de Educação do Estado do Acre - Gerência de Educação Escolar Indígena.

"* Discente do Programa de Pós-Graduação em História Social - Instituto de Ciências Humanas e Letras (ICHL) - Universidade Federal do Amazonas (UFAM) / Técnico em Educação Escolar Indígena - Secretaria Estadual de Educação do Acre (SEEAC) - Gerência de Educação Escolar Indígena. marcio.rbr_mao@hotmail.com / (68) 8414-4289.
} 
A questão apresentada como título do presente ensaio surge em um curso de formação de técnicos em educação, no ano de 2008, promovido pela Gerência de Educação Escolar Indígena do Estado do Acre. Nessa ocasião, os participantes entram em contato com os resultados de um curso de formação para os professores indígenas no ano de 2006. Nessa oportunidade, os professores em formação foram indagados, com a pergunta acima, com o objetivo de pensar e sofrer o papel e as funções das escolas indígenas. As questões recorrentes colocadas pelos cursistas indígenas, naquele momento, aportavam necessariamente na idéia de que a educação estaria proporcionando a “"aquisição de instrumentos de análise' do mundo dos não-índios” (WILMAR, 2005). Os argumentos colocados pelos professores para sustentar tal idéia iam da noção de "aprender língua portuguesa e matemática para fazer negócios e assinar documentos", passando pela idéia de "que as crianças [devem] aprender mais português para poder ajudar o pai na venda de produtos e na compra" ou a noção "de apreender para defender as nossas terras, avisar o IBAMA ou assinar documentos", entre outros.

A reflexão a respeito dos significados da perspectiva colocada pelos professores é extremamente importante não só porque nos serve de subsidio para pensarmos que os referidos argumentos, utilizados para justificar essa opção de escola, dizem respeito à situação de algumas etnias que compõem o grupo lingüístico Aruak, e que essa opção diz muito sobre sua situação de contato, seus processos de territorialização e a relação muito intensa e próxima com a sociedade nacional; Mas também porque nesses casos específicos, a "obsessão pelo estrangeiro e pelos os outros tipos de Outros" (ERIKSON, 1986), em se tratando de educação escolar, não é uma peculiaridade dos grupos Pano, Mas se configura como uma especificidade de boa parte das referidas etnias. Nesses casos, a fronteira que há entre o "Eu" e o "Outro" no que diz respeito ao processo de construção da educação escolar, se traduz na forma de mimetismo. Trata-se de um movimento recorrente em muitos grupos indígenas das terras baixas sul-americanas, que foi identificado por Kelly (2005) como o processo de "virar branco". Nesse processo, as afirmações: "agora somos civilizados", para justificar os resultados de algum serviço público, ou "aprender lingua portuguesa e matemática para faz̨er negócios e assinar documentos", para argumentar sobre a importância do acesso do mesmo serviço, são extremamente significativas para clarear o significado cotidiano das relações que esses mesmos grupos têm com os "brancos" e o Estado (KELLY, 2005).

116 Somanlu, ano 8, n. 2, jul./dez. 2008 
A constatação dos argumentos levantados também nos serve para pensarmos que tais justificativas partem da crença de que, ao acessarem os conhecimentos da sociedade não-indígena, estariam necessariamente garantidos os direitos de trânsito nessa mesma sociedade ou garantido o "processo de virar branco". Esse tipo de noção não é um ponto de vista particular dos professores e lideranças indígenas sobre a escola em suas comunidades. Essa perspectiva parece-me ser o balizamento por excelência das diversas ações no Estado dos diferentes Agentes Educacionais Indigenistas. Os Planos Políticos Pedagógicos em desenvolvimento nas diferentes escolas indígenas do Estado, quando não estabelecem uma reprodução automática dos princípios contidos nos documentos governamentais, incorrem necessariamente na construção de um currículo reproduzido das escolas não-indígenas, de acordo com as exigências dessa mesma estrutura escolar.

Em suma, o que move a ação tanto dos professores indígenas, quanto de alguns técnicos do governo e de instituições não-governamentais é a quase ingênua noção de que a função da escola indígena consistiria exatamente na possibilidade de que, ao acessarem os conhecimentos não-indígenas, estariam automaticamente construindo o espaço de participação dos grupos indígenas na sociedade não-indígena. O que essa visão de educação não percebe é que o espaço de participação desses grupos, há centenas de anos, já vêm sendo garantido, ou seja, sua inclusão já é algo extremamente recorrente em nossa sociedade. No entanto, a inclusão indígena, nos termos em que se coloca, ou seja, nos termos não-indígenas, localiza-se exatamente na ínfima parcela reservada aos excluídos.

A busca por um espaço possível deve se estabelecer, mas não a partir de uma lógica integracionista, cujos critérios de competência e qualidade são forjados a partir de referenciais não-indígenas. A "captura do estrangeiro", nesse caso, não se estabelece na direção da antropofagia (nos termos dos "ditos modernos"). Nesse processo de deglutição, as possíveis proteínas são necessariamente o que garante a sua condição de "sociedade subalterna". Pode-se mesmo dizer que a opção de escola de que esses grupos fazem parte, em boa medida, dá esperança de, ao construir "A capacidade de imitar, e imitar bem, é, em outras palavras, a capacidade de tornar-se outro." (WALTER BENJAMIN apud LAGROU 2002, p. 29). No entanto, esse processo de tornar-se outro implica na incorporação, por parte dos grupos em questão, de um conjunto de valores, atitudes e princípios, ditos das sociedades não-indígenas, em detrimento dos valores, atitudes e princípios indígenas. Tal pro- 
cesso não pode ser confundido com a ideia de perda cultural, já que isso implicaria em uma simplificação grosseira, além de uma noção de cultura com que não compartilhamos. Mas pensarmos, fundamentalmente, que a semelhança nesse caso não garantirá aos grupos em questão as mesmas condições de oportunidades e direitos ao acessarem os saberes da sociedade nacional.

O que há, na base de todo saber, sobretudo, o saber dito ocidental, é uma complexa e multifacetada representação das estruturas de poder. Esse poder que sempre esteve na base dos procedimentos de sujeição dos povos indígenas, entre outros. Então, não seria apenas a partir do domínio dos códigos da "sociedade envolvente" que estariam se inserindo nessa difícil trajetória heterotópica. Não seria o acesso a esse saber, por parte dos povos indígenas, que iria resolver suas questões, e sim a possibilidade de construir competências que garantam o trânsito nessas teias de poder. Talvez o que garanta esse trânsito seja não a reprodução das "escolas dos brancos" nas terras indígenas, mas o fazer com que a educação indígena, que tem como apelo retórico os chavões "diferenciada, bilíngüe e intercultural”, possa ser construída tendo como eixos norteadores os valores, atitudes e princípios dos povos indígenas, nos termos dos próprios indígenas.

Se levarmos radicalmente a sério esses princípios práticos, colocados nos termos indígenas, poderemos romper essa visão recorrente com que se tratam os programas de educação escolar indígena. A visão redentora da educação escolar indígena que exalta "as belezas e benesses" desse processo de escolarização é o que garante que a escola indígena continue tomando como parâmetro a noção de competências e habilidades da sociedade não-indígena que devem ser internalizado pelos indígenas. A escola indígena construída nesses termos continua garantindo a manutenção histórica do processo integracionista e missionário. O que garante a manutenção desse processo é o fato de que os princípios que norteiam a construção da educação escolar indígena não são colocados nos termos indígenas, e sim nos termos da lei. E o grande desafio que se coloca é identificar e multiplicar os termos indígenas.

Então, se quisermos fazer de outra forma, que não essa forma usual e recorrente de fazer educação escolar indígena que continua integrando e catequizando (em novos e velhos catecismos), e que garante um processo de formação de sub-autonomia, ou em outro caso, de competências subalternas, deveremos nos preocupar em construir um contexto onde o processo de construção da escola indígena seja protagonizado

118 Somanlu, ano 8, n. 2, jul./dez. 2008 
pelos próprios indígenas, e não pelo Estado ou outra instituição (isso não quer dizer que sua participação nesse processo seja dispensável) e que seus princípios sejam construídos nos termos dos "nativos", levando radicalmente a sério suas categorias de pensamento. E que estas categorias "nativas" devam ser os norteadores da construção de um plano político-pedagógico coerente e exeqüível.

A pergunta que se coloca é: o que significa dizer "levar radicalmente a sério os referidos princípios práticos ou as categorias de pensamento indígena na construção da escola indígena?" Talvez a questão a ser respondida não seja o que quer dizer, pois, em se tratando de Educação Escolar Indígena, boa parte do que se diz está longe de ser regra para a ação dos agentes educacionais indigenistas. Então, o que se pode indagar é se é possível construir uma escola indígena a partir dos termos dos indígenas. E se isso é possível, se as categorias de pensamentos forem reconhecidas e respeitadas como conhecimentos válidos, e não como na postura etnocêntrica que as considera como etnoconhecimentos ou conhecimentos tradicionais; nessa construção, a escola indígena deveria ser indiferenciada, já que seria impossível construí-la tomando como parâmetro a escola não-indígena. (WILMAR, 2005)

Como já foi dito, a tendência em construir as escolas indígenas tomando como referência a estrutura educacional não-indígena é algo extremamente recorrente no trabalho dos diferentes agentes educacionais no Estado. O resultado direto dessas ações são as escolas indígenas que se organizam em torno dos princípios de seriação, ano letivo de dez meses, organização por faixa etária, currículo sendo orientado pela noção da disciplina e professor por disciplina, entre outras coisas. Nesse caso especifico, o que garante para as escolas indígenas a adjetivação "diferenciada", designando necessariamente diferente da escola da cidade, seria não a forma, estrutura e conteúdos da mesma, mas as condições infra-estruturais que, no caso das escolas indígenas, são muito inferiores em relação às "escolas dos brancos".

A construção de uma escola indígena possível não deve ser norteada a partir de princípios das escolas não-indígenas, construídas para atender os interesses da sociedade não-indígena. Tal construção, talvez, possa partir de um esforço de imaginação intelectual, esforço intelectual não unicamente dos diferentes agentes educacionais envolvidos com a questão, mas, fundamentalmente, tomar como parâmetro de forma e conteúdo da escola indígena a imaginação conceitual das culturas "nati-

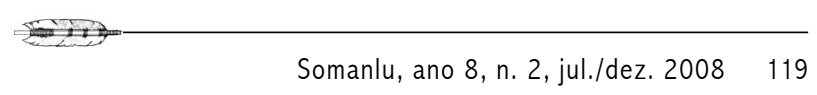


vas". Tal perspectivismo indígena, tomado aqui como válido para pensar as escolas indígenas, implica tomar a referida imaginação como relacional e relativa ao ponto de vista das relações sociais que ela implica; implica, ainda, pensar a influência da escola não-indígena como a alteridade em questão e, nesse sentido, como alteração, ou seja, correlata aos diferentes processos de atualização (NUTI, 2003).

A proposta é relacionar a imaginação "conceitual" dos diversos agentes educacionais com a referida imaginação indígena, tomada aqui também como conceitual (VIVEIROS DE CASTRO, 2002). A implicação desse processo relacional, tomado como instrumento de análise e de ação, é a construção de um projeto de escola que se funda na idéia de que é possível relacionar-se com modos diversos de pensar a temporalidade, a escola e a história. Pensar a construção da educação escolar indígena, tomando como princípio a complexidade e sofisticação do pensamento ameríndio, implica em deslocarmos nossa atenção da recorrente reflexão sobre educação escolar indígena, que se debruça sobre a tentativa de saber se a escola caminha ou não na contramão da experiência da intervenção missionária, ou se essa "nova" proposta educacional garante a manutenção de uma intervenção civilizadora. A questão que se coloca é ir para além da pergunta recorrente de saber se é possível inverter os sinais de uma longa história (NUTI, 2003, p. 70).

A discussão recorrente colocada acima implica em pensar a cultura indígena como um conjunto de "traços culturais" que, de acordo com a ação da escola, nesse caso específico, podem ser perdidos, levando a um processo de perda da cultura. A cultura, ao contrário, deve ser definida não a partir de "seus traços constitutivos, mas sim o estabelecimento da fronteira entre um e outro, o que é feito pela atribuição da diferença, pelos traços diacríticos" (COHN, 2005, p. 80). Se fizermos uma torção em nossas categorias de análise e nos aproximarmos da noção de que é vetada à cultura indígena a condição de integridade e, portanto, a impossibilidade de ser preservada, estaremos necessariamente nos aproximando de uma reflexão que aponta para o entendimento de que os processos de alteração que vêm ocorrendo com os povos indígenas, como resultado da ação da escola, são parte de um processo maior de alteração. O que devemos refletir, então, é a respeito da sobrevivência física e cultural dos povos indígenas, questão que impõe um conjunto de iniciativas objetivas, dentre as quais, a educação.

E se nos preocuparmos com essa questão a respeito da escola, devemos nos debruçar sobre os significados da escola para os diferentes grupos que a mantêm em suas aldeias: como esses grupos se apropriam da escola, da escrita, da educação formal,

120 Somanlu, ano 8, n. 2, jul./dez. 2008 
entre outras coisas, por meio de "processos de ressignificação através de cosmologias, práticas xamanísticas, dinâmicas políticas internas, impregnando essa nova experiência de elementos culturais e históricos particulares" (NUTI, 2003:71). E se caminhássemos nessa direção, então estaríamos nos preocupando com o fundamental da educação escolar indígena, e o que seria o fundamental? Darmos atenção às formas de "organização da experiência e da ação humana por meios simbólicos” (SAHLINS, 1997).

Nesse sentido, estaríamos pensando a construção da escola indígena bem mais próxima dos princípios colocados acima de "valores, atitudes e princípios" que substituem as adjetivações retóricas contidas nos vários documentos governamentais de "diferenciada, bilíngüe e intercultural”. Estaríamos necessariamente respeitando, na escola, e tomando como condição para a existência da escola, que, para os grupos indígenas "as pessoas, relações e coisas que povoam a existência humana manifestam-se essencialmente como valores e significados — significados que não podem ser determinados a partir de propriedades biológicas ou físicas" (SAHLINS, 1997, p. 87).

E se nossa intenção é refletir sobre a sobrevivência cultural desses povos, e se entendemos que suas culturas não podem ser determinadas a partir de propriedades biológicas ou físicas, e sim que pode se assemelhar às formas de organização da experiência e da ação por meios simbólicos, então, necessariamente, iríamos associar a manutenção cultural desses povos à manutenção desses meios simbólicos pelos quais os grupos indígenas organizam seu mundo. E se estamos preocupados a respeito de saber se a escola ajuda ou prejudica nesse processo de manutenção, ou se temos claro que o papel da escola indígena é de ser o instrumento para tal processo, então temos necessariamente de aceitar que, para que a escola sirva de instrumento de tal empreitada, é necessário que sua condição de possibilidade sejam os referidos meios simbólicos, mas sobretudo, os objetos desses meios simbólicos e as formas pelas quais eles atuam. Nessa direção, a construção da educação escolar indígena que trabalha no sentido de garantir a sobrevivência cultural dos povos indígenas, por meio da manutenção de seus meios simbólicos, deve necessariamente se opor à idéia de que a escola deva propiciar a possibilidade de aquisição de instrumentos de análise do mundo dos não-indios.

Ao contrário, a condição para que a escola trabalhe para tal empreitada é que tome como ponto de partida de sua construção as estruturas simbólicas do pensamento ameríndio e suas formas possíveis de manutenção; e, nesse sentido, propicie a aquisição de instrumentos de análise dos valores e significados que compõem a cultura em questão: o mundo dos não-indígenas aparece aqui como mais um dos significados

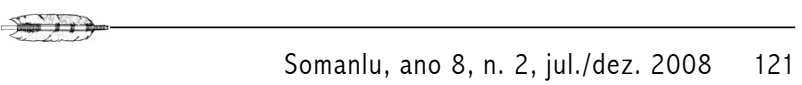


que compõem essa estrutura cultural, um significado muito específico e, especialmente, perigoso para os povos indígenas. Nesse caso, a escola que se organiza dessa forma, tomando como parâmetro o indígena (valores, atitudes e princípios) e não o não-indígena (diferenciada, bilíngüe e intercultural), atua como dispositivo de um processo de "domesticação simbólica" desse significado pernicioso. Ou, como mostra Albert (2002), um processo de "pacificação às avessas", um processo de amansamento da escola que neutraliza as nefastas influências da sociedade nãoindígena no que diz respeito ao processo de construção da educação escolar indígena.

A proposta de tomar como ponto de partida da escola indígena o pensamento indígena, e o mundo não-indígena como apenas uma das representações contidas nesse mesmo pensamento, não significa que defendemos o distanciamento dos povos indígenas dos conhecimentos ditos "técnico-científicos". Mas, fundamentalmente, percebermos que o ponto de partida para a construção do processo de emancipação dos povos indígenas nasce exatamente no momento em que percebem as diferenças inerentes entre o conhecimento não-indígena e o conhecimento indígena. Percebem

que o que distingue os conhecimentos tradicionais indígenas dos nossos conhecimentos (tradicionais ou científicos) é muito mais a forma que o conteúdo, é, além disso, a idéia mesma de conhecimento: a imagem de quem conhece, a imagem do que há a conhecer, e a questão de para que, ou melhor, por que se conhece (VIVEIROS DE CASTRO, 2002, p. 3).

A questão que se coloca aqui não é nem saber que "o discurso sobre os conhecimentos tradicionais enfatiza os conteúdos desse conhecimento, separando tais conteúdos de sua forma" (idem), produzindo nesse processo um movimento de "descontextualização" da cultura. Mas é constatar que a experiência social do mundo indígena é muito mais ampla e variada do que a tradição científica conhece e considera como importante, e que a compreensão indígena de mundo excede em muito a compreensão ocidental do mesmo (SANTOS, 2001). A proposta defendida aqui não pode ser confundida com as recentes valorizações utilitaristas e etnocêntricas em relação às culturas indígenas, que partem da noção de instrumentalização de nossa relação com os referidos povos no sentido de só admitirem "o direito à existência dos

122 Somanlu, ano 8, n. 2, jul./dez. 2008 
outros se estes servirem a algo para nós” (VIVEIROS DE CASTRO, 2002, p. 3). A preocupação aqui é mais de construir parâmetros para uma escola indígena que não incorra nas velhas práticas integracionistas (ou assimilacionista) baseadas na dificuldade de se relacionar com a diferença ou no desejo de eliminá-la.

A defesa dessa proposta implica necessariamente no rompimento da noção que vem norteando a construção da educação escolar indígena na América Latina. A idéia de que

a educação intercultural seria vista como instrumento de inclusão das minorias e de atribuição de poder às populações que estão às margens da cultura dominante. A idéia subjacente a essa visão seria que, através do domínio tanto dos seus códigos específicos como dos códigos 'ocidentais' ou nacionais, as minorias poderiam reivindicar um espaço na sociedade e nas economias nacionais e globais (COLLET, 2003: 123).

O instrumento de inclusão dos povos indígenas no processo de reivindicação de espaço na sociedade nacional não se estabeleceria nesses termos, ou seja, através do “domínio dos códigos 'ocidentais'. Trilhar esse caminho significaria a manutenção de um processo histórico de exclusão cujo objetivo é eliminar a diferença. É certo que a diferença, ou, em outros termos, as distinções étnicas, têm como base de sua construção a interação e aceitação em relação aos termos de suas fronteiras. Isso, já se sabe, não implica em sua destruição ou aculturação, mas, ao contrário, as diferenças culturais persistem e são produzidas por meio do contato interétnico. No entanto, esse contato, ou especificamente, a relação entre grupos étnicos e a sociedade nacional tem que ser muito bem delimitada e os termos dessa relação têm que ser negociados e definidos. Essa relação, ou como mostra Barth (2000), o vínculo positivo, não deve ser estabelecido sem que se tenha como base da interação referências da identidade étnica. No caso especifico da educação escolar indígena, que, em sua construção, não toma como parâmetro essas considerações de Barth, tem-se a tendência a garantir a manutenção histórica do espaço ocupado pelos povos indígenas na sociedade nacional; como mostra o próprio Barth, "a forma extrema da posição de minoria" (BARTH, 2000, p.56) que se localiza exatamente nas margens, ou de outra forma, "o lugar das periferias". O importante nesse processo é reconhecer que a implicação disso é 
uma drástica redução das diferenças culturais entre os grupos étnicos [que] não se relaciona de maneira simples com uma redução na relevância das identidades étnicas em termos organizacionais ou com uma ruptura dos processos de manutenção de fronteiras (BARTH, 2000, p. 59).

As considerações de Barth são significativas para pensarmos os argumentos levantados pelos professores indígenas a respeito da escola. A busca por um espaço de participação na sociedade nacional, que se estabelece nos termos referidos por Collet (2003), leva esses grupos a traçar estratégias de inclusão que se baseiam na tentativa de passar para a sociedade em questão incorporando-se a ela; ou, em outro caso, aceitar a condição de minoria, tentando acomodar as suas supostas deficiências em um processo de redução dos diferenciadores culturais (BARTH, 2000). Em ambos os casos, a opção de educação formal que fazem, ou seja, aquela que instrumentaliza para o domínio dos "códigos ocidentais", atua como um dos agentes do processo amplo de alteração dos grupos étnicos.

No entanto, a alteração não é o problema em questão, já que é sabido que, na inconstância do contexto indígena, a transformação e as inovações se constituem no que é de mais tradicional entre esses povos. A questão relevante que se coloca é que a inclusão dos grupos em questão por meio da escola não pode se estabelecer via a acomodação de supostas deficiências e na redução das diferenciações culturais. Como já propusemos, a escola deve se relacionar e multiplicar modos diversos de pensar a temporalidade, a escola e a história. E nesse sentido, a condição para a manutenção das fronteiras étnicas é necessariamente a manutenção das diferenciações culturais; esse processo ocorre quando a lógica de um grupo dito minoritário não é subsumida pela lógica do pretenso grupo majoritário. A proposta é garantir a existência desse limite tênue e fluido, que é a fronteira entre as referidas sociedades.

A manutenção da referida fronteira, ou nos termos de Boaventura, a "zona de contato", se estabelece a partir de movimentos de reinvenção da experiência escolar entre os povos indígenas; essa reinvenção, entendida aqui como base do processo de acesso à cidadania cultural desses povos, depende de um significativo esforço de tradução, "um procedimento capaz de criar uma inteligibilidade mútua entre experiências possíveis e disponíveis sem destruir a sua identidade" (SANTOS, 2003, p. 4). Esse trabalho de tradução, segundo o autor citado, cria as condições para emancipação social concreta dos grupos em questão. Tal processo que implica em relações não destrutivas

124 Somanlu, ano 8, n. 2, jul./dez. 2008 
que tem como base garantir na escola a visibilidade de "realidades ausentes por via do silenciamento, da supressão e da marginalização, isto é, as realidades que são ativamente produzidas como não existentes" (SANTOS, 2003, p. 20).

Esse significativo processo democrático que nasce na escola permite, por meio dos diferentes processos de transmissão, o reconhecimento de diferentes práticas e atores sociais válidos. Nesse sentido, a construção das escolas indígenas deve necessariamente partir da oposição da noção de que "a ciência moderna e a alta cultura [leia-se: cultura "ocidental'] [são] os critérios únicos de verdade e de qualidade estética, respectivamente" (idem, p 12). Essa oposição parte da perspectiva de reconhecer que existe uma pluralidade de saberes que operam em contextos e práticas sociais próprias, e que os processos de transmissão da educação formal têm que identificar qual saber cabe para determinado contexto social.

Esse procedimento visa "libertar as práticas sociais [sobretudo as indígenas] do seu estatuto de resíduo, restituindo-lhe a sua temporalidade própria e, assim, a possibilidade de desenvolvimento autônomo". Em linhas gerais, as escolas indígenas devem ter como princípio básico a possibilidade de garantir à sua clientela a possibilidade de construir a capacidade de reconstruir os diferenciadores culturais que garantem a manutenção de suas fronteiras por meio da valorização de suas identidades étnicas. Ou, em outros termos, fazer o caminho caminhando, seguindo em frente no caminho de volta.

\section{Referências}

BARTH, Fredrik. O guru, o iniciador e outras variações antropológicas. Tradução de John Cunha Comerford. Rio de Janeiro: Contra Capa Livraria, 2000.

COHN, Clarice. Culturas em transformação: os índios e a civilização. São Paulo em Perspectiva, 2001, v. 15, n. 2, ISSN 0102-8839.

COLLET, Celia Leticia Gouvêa. Interculturalidade e Educaşão Escolar Indigena: um breve bistórico. Cadernos de educação escolar indígena $-3^{\circ}$ grau indígena, Barra do Bugres, UNEMAT, v. 2, n. 1, 2003.

D’ANGELIS, Wilmar da Rocha. Ensino Conteudístico na Escola Indígena: atitudes indiferenciadas na escola "diferenciada". In: REUNIÃO DE ANTROPOLOGIA DO MERCOSUL: GT 32 - Educação Escolar Indígena: uma mirada desde La Antropologia. Montevideo, Novembro. 2005 (Prelo) 
VIVEIROS DE CASTRO, Eduardo. O nativo relativo. Mana, 2002, v. 8, n. 1, ISSN 0104-9313.

- A natureza em pessoa: sobre outras práticas de conbecimento. In: ENCONTRO "VISÕES DO RIO BABEL. Conversas sobre o futuro da bacia do Rio Negro". Instituto Socioambiental e a Fundação Vitória Amazônica, Manaus, 22 a 25 de maio de 2007. (prelo)

ERIKSON, Philippe. Uma Singular Pluralidade: A Etnohistória Pano. In: História dos indios do Brasil. São Paulo: Companhia das Letras/FAPESP/SMC, 1992, p. 239252.

LAGROU, Elsje Maria. O que nos diz a arte Kaxinawa sobre a relação entre identidade e alteridade? Mana, 2002, v. 8, n. 1, ISSN 0104-9313

KELLY, José Antonio. Notas para uma Teoria do "Virar Branco". Mana, 2005, v. 11, n. 1, ISSN 0104-9313.

ALBERT, Bruce; RAMOS, Alcida Rita. Pacificando o Branco: cosmologias do contato no norte - amazônico, São Paulo: Editora UNESP/Imprensa Oficial do estado, 2002.

SAHLINS, Marshall. O pessimismo sentimental e a experiência etnográfica: por que a cultura não é um “objeto" em via de extinção (parte I). Mana, 1997, v. 3, n. 1, ISSN 0104-9313.

O "pessimismo sentimental" e a experiência etnográfica: por que a cultura não é um "objeto" em via de extinção (parte II). Mana, 1997, v. 3, n. 2, ISSN 0104-931

SANTOS, Boaventura de Souza (Org.). Osprocessos de globalização: globalização, fatalidade e utopia? Porto: Afrontamento, 2001. 31-106.

TRANSFORMAÇÕES INDÍGENAS. Os regimes de subjetivação ameríndios à prova da história. PROJETO PRONEX - NUTI. Rio de Janeiro; Florianópolis: SETEMBRO DE 2003. (Prelo)

126 Somanlu, ano 8, n. 2, jul./dez. 2008 